\title{
ADAPTAÇÕES DOS PESCADORES ARTESANAIS AOS IMPACTOS AMBIENTAIS SOBRE OS MANGUEZAIS DO ESTUÁRIO DA BAIXADA SANTISTA
}

\section{Wilson Moreira Junior ${ }^{1}$}

RESUMO: Os manguezais são ambientes de grande importância ecológica e que propiciam diversos benefícios à humanidade, com destaque para as comunidades tradicionais e de pescadores que dele dependem diretamente. Com o crescimento industrial, portuário, urbano e turístico da Baixada Santista, litoral central do Estado de São Paulo, os manguezais sofreram fortes impactos ambientais negativos, o que acarretou perda de extensas áreas e desequilíbrio ecológico, conseqüentemente influenciou o modo de explotação de seus recursos e contribuiu para o processo de empobrecimento e desestruturação das comunidades de pescadores artesanais. Este trabalho objetiva discutir como os impactos ambientais aos manguezais da região afetaram o modo de produção e de vida dos pescadores artesanais e quais foram às adaptações deles a estes impactos. O método de pesquisa foi entrevistas nãoestruturadas e semi-estruturadas, estas tratadas sob a luz da História Oral em quatro comunidades localizadas no estuário da Baixada Santista, são elas: Sítio Conceiçãozinha, Sítio Cachoeira, Ilha Diana e Vila dos Pescadores. Constatou-se diferentes adaptações desenvolvidas nos seus modos de produção a fim de superar as perdas de recursos ocorridas pela degradação do manguezal. As respostas dadas pelas comunidades

\footnotetext{
${ }^{1}$ Biólogo. UNESP.wilmorjr@hotmail.com
} 
originam-se da necessidade de sobrevivência e da percepção que elas têm dos impactos e suas possibilidades de executarem novas atividades para compensarem as perdas.

Palavras-chave: Manguezal. Pescadores artesanais. Impactos ambientais.

\section{INTRODUÇÃO}

Os manguezais são considerados um ecossistema costeiro, de transição entre os ambientes terrestres, fluvial e marinho, ocorrem em regiões abrigadas e estão sujeitos ao regime das marés (CETESB, 1991), sua localização se restringe à faixa entre o ponto mais alto da maré alta e o ponto mais baixo da maré vasante (LACERDA, 1984). Constitui-se de espécies de vegetais lenhosas características (LAMPARELLI, 1999), essa vegetação é comumente chamada de mangue e habitam um ambiente fortemente seletivo, já que as plantas tem que se desenvolver em um solo bastante inóspito. De acordo com Ferri (1980), as condições que predominam, são: solo alagado, movediço, pouca disponibilidade de oxigênio e alto teor de salinidade.

Em relação à importância econômica, os manguezais são fontes de diversos recursos para explotação direta e indireta. Podemos citar da forma direta o extrativismo, a agricultura e a silvicultura, um exemplo é a utilização de madeira do mangue para construções de casas, cercas, instrumentos de pesca, barcos, artesanatos e lenha; obtenção do tanino para curtir o couro e para tingir e proteger redes de pesca; coleta de crustáceos e moluscos; produção de mel entre outros (LAMPARELLI, 1999).

O manguezal também propicia outras funções e serviços como: a estabilidade da linha da costa, evitando assoreamento de rios e do estuário; a proteção contra a invasão do mar, protegendo áreas emersas; habitats para a fauna e flora; berçário para inúmeras espécies de peixes, aves e crustáceos; grande produção primária de biomassa; área para recreação, turismo e educação ambiental (DIEGUES, 1988; DIEGUES, 2002).

Os manguezais são explotados a muito tempo, desde as populações dos sambaquis, posteriormente pelos indígenas que viviam no litoral ou o que visitavam 
periodicamente e atualmente pelas comunidades caiçaras e de pescadores artesanais (DIEGUES, 1988; DIEGUES, 2002).

Existem comunidades ribeirinhas que mantêm grande inter-relação com os manguezais, tendo grande dependência de seus recursos. Sendo que boa parte das proteínas de sua alimentação provém do manguezal, utilizam suas ervas medicinais, além da madeira para suas construções e lenha (GRASSO e TOGNELLA, 1995).

Mesmo os manguezais sendo extremamente importantes na manutenção da dinâmica física e biológica do estuário, estabilizando as drenagens e sendo responsável por uma complexa e rica cadeia trófica (CETESB, 1991) e de uma intensa relação com comunidades tradicionais, tanto nos aspectos econômicos e sociais, quanto nos culturais (DIEGUES, 1988), eles vêm sendo duramente afetados por ações antrópicas predatórias nocivas ao seu equilíbrio ecológico na maioria das vezes provocada pela sociedade urbana-industrial. Comunidades tradicionais que se inseriram em uma lógica de mercado capitalista, também, se tornaram demasiadamente agressiva a esses ambientes a fim de atender uma demanda externa da comunidade orientada por outra lógica de produção e consumo. Todavia a explotação pelas comunidades ribeirinhas locais é exercida a muitas gerações e que esse uso tradicional não comprometeu a capacidade de resiliência desses ambientes, pois há um conhecimento ecológico que orienta e institui regras para a explotação.

A explotação é elemento revelador da estrutura das relações de produção nas comunidades tradicionais e pesqueiras, porém, não tem traços exclusivos ou estáticos dentro da comunidade e com seus interlocutores. Os grupos apresentam formas diversificadas de produção, estas não são estanques e podem permanecer estáveis, ou alternarem ou coexistirem entre si. A explotação dos manguezais, além de dar indicações preciosas sobre a estrutura de produção da comunidade, também, indica como esta se relaciona com outros setores da sociedade.

No presente trabalho, são discutidos os principais impactos ambientais de origem antrópica, na ótica das comunidades estudadas, na região do Estuário da Baixada Santista, com reflexos na deterioração dos manguezais e conseqüentemente da pesca. 
Isso através da percepção dos pescadores artesanais e do levantamento feito pelo autor em campo e da bibliografia e documentos consultados.

A legislação brasileira, através da resolução CONAMA 01/1986, em seu artigo 1ำ define impacto ambiental como:

...qualquer alteração das propriedades físicas, químicas e biológicas do meio ambiente, causadas por qualquer forma de matéria ou energia resultante das atividades humanas que, direta ou indiretamente, afetam: I - a saúde, a segurança e o bem-estar da população;/ II - as atividades sociais e econômicas;/ III - a biota;/ IV - as condições estéticas e sanitárias do meio ambiente;/ V - a qualidade dos recursos ambientais (SANCHES, 2006).

De acordo com SANCHES (2006) existem diversas definições de impacto ambiental, quase todas elas largamente concordantes e seus elementos básicos, porém formuladas de maneiras diferentes. Este autor apresenta vários exemplos de definições de impactos ambientais e faz uma ampla discussão sobre esse conceito.

O presente trabalho tem como objetivo discutir como os impactos ambientais aos manguezais da Baixada Santista afetaram o modo de produção e de vida dos pescadores artesanais e quais foram às adaptações deles a através de uma perspectiva histórica a partir de relatos de memória e demonstrar sua diversidade e versatilidade em ambientes de fortes conflitos sociais e ambientais.

\section{MATERIAIS E MÉTODO}

Para esta pesquisa tomou-se como base quatro comunidades de pescadores artesanais, caiçaras e moradores ribeirinhos, do estuário da Baixada Santista, SP, em que a pesca artesanal era uma importante atividade econômica, cultural e de identidade, são elas: Sítio Cachoeira (2353'4,92”S - 469'51,61'W), com dez entrevistados, localizada no Canal de Bertioga, Sítio Conceiçãozinha (2358'33,91'S - 46¹7’5,20’W) no Estuário de Santos, com onze entrevistados, ambas pertencentes ao município de Guarujá; a Ilha Diana $\left(23^{\circ} 55^{\prime} 2,82^{\prime \prime} S\right.$ - 4618'18,07'W) que se encontra às margens do rio Diana na 
confluência do Canal de Bertioga com o Estuário de Santos no município de Santos, com

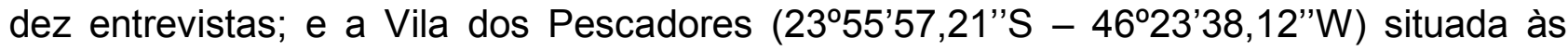
margens do rio Casqueiro, em Cubatão, com treze entrevistas.

Essas comunidades foram eleitas, para a presente pesquisa, por se localizarem em pontos distintos do estuário com diferentes conflitos socioambientais.

A pesquisa teve início através de contatos prévios, em campo buscando uma melhor aproximação das pessoas e da região a ser investigada. Assim, pode-se apresentar a proposta de trabalho realizada através de conversas com membros das comunidades. Os trabalhos sistemáticos de observação direta e entrevistas iniciaram-se no final de 2006 e perdurou por todo ano de 2007, no qual foram realizadas diversas visitas a esses locais para a realização de contatos, conversas, entrevistas e observações de campo. As comunidades estudadas já eram conhecidas do autor devido à curso de Especialização, aparecer para a Procuradoria da República, à realização de inúmeros foros de discussão da questão ambiental, pesqueira e das comunidades tradicionais da região no qual o autor e alguns membros das comunidades participaram.

As entrevistas foram gravadas e depois transcritas em cadernos para serem analisadas. Usou-se de caderneta de campo para anotar as observações e informações obtidas em campo. O processo de entrevista se deu utilizando e respeitando a forma de linguajar característica das comunidades e evitou-se a utilização de termos técnicos e linguagem diferente do cotidiano local.

Preferiu-se, a princípio, entrevistar pescadores e moradores mais velhos em idade, preferencialmente próxima ou superior a sessenta anos, porém no transcorrer dos trabalhos abriram-se exceções, pois outros depoentes puderam contribuir com informações relevantes, e assim aumentou-se o número de depoimentos e pontos de vista levantados.

Para esta pesquisa utilizou como base entrevistas não-estruturada e semiestruturadas com perguntas abertas, além de depoimentos orais de pescadores, caiçaras e moradores ribeirinhos, preferencialmente àqueles reconhecidos pela comunidade que são conhecedores sobre os temas tratados da região do estuário de Santos, SP. Os 
informantes foram escolhidos a partir de contatos prévios com as comunidades locais, e estratificados em função de seu conhecimento sobre a atividade pesqueira, a ecologia estuarina e a história da população local e por ter informações relevantes a este projeto. Desse modo, procurou-se traçar um painel da visão que os pescadores e as comunidades têm dos problemas da região, reconhecendo, inclusive, as diferenças internas ao grupo social. Não cabe, neste texto, a discussão teórica dos métodos utilizados, um aprofundamento maior sobre o entrevistas não-estruturadas e semi-estruturadas podem ser encontradas em CRUZ NETO (1996), MINAYO (2000), VIERTLER (2002), LÜDKE e ANDRÉ (1986); e História Oral e estudos de memória em PASSARINI (1993), GUIMARÃES NETO (2000), FREITAS (2002), MEIHY, (2005), entre outros autores.

Foi utilizado na pesquisa dados secundários disponíveis nas bibliografias referentes à pesca artesanal, populações tradicionais, caracterização da região da Baixada Santista, manguezais e sobre os impactos ambientais.

De posse dos depoimentos orais, do levantamento e análise da bibliografia, dos relatórios técnicos e outros documentos, pretendeu-se obter elementos para discutir as relações das comunidades com o meio ambiente, suas transformações e as respostas que as populações tradicionais dão aos impactos existentes.

\section{RESULTADOS E DISCUSSÃO}

Segundo Lacerda (1984), pode-se dividir as principais ameaças à integridade dos manguezais em causas naturais e em ações antrópicas. O relatório da CETESB (1991) indica que os principais danos dos manguezais da Baixada Santista são relacionados a atividades humanas.

Varjabedian (1995), se referindo à duração e atuação de tensores sobre os manguezais nos escreve que podem ser identificados dois tipos: uma aguda quando ocorre por um período curto de tempo e crônica, quando ocorre por prazos de tempo mais longo, esses impactos, agudos ou crônicos podem atuar simultaneamente. O mesmo autor classifica os fenômenos naturais, principalmente os de baixa e média intensidade, 
como tensores agudos, afetando os manguezais temporariamente, sendo quase sempre possível o restabelecimento da qualidade anterior. As ações antrópicas, principalmente acidentes que geram contaminação por petróleo e produtos tóxicos, atuam como tensores crônicos, sendo seus impactos sentidos por longo prazo e até mesmo podendo matar o manguezal.

Há impactos que têm características agudo e crônico, pois no momento que se manifesta impõe um duro golpe ao manguezal, muitas vezes suprime algumas áreas e depois a permanência das estruturas instaladas e os dejetos lançados por ela agridem o manguezal de forma continua, inclui-se nesse perfil a ação industrial, portuária, urbana e suburbana.

Depois que os manguezais sofreram uma ação de destruição total ou parcial, se a causa for removida, há uma tendência à voltar sua composição e estrutura original, isso vai depender da duração, eficiência, intensidade e extensão espacial dos fatores de impacto, como do próprio impacto (VICENTE, 1995).

O manguezal é um importante ecossistema para as comunidades estudadas, pois elas os explotam diretamente, além dos beneficios indiretos que ele proporciona aos ambientes de entorno. Constatou-se diferentes maneiras de uso dos recursos dos manguezais de acordo com as comunidades, tempo, pescadores e sexo. Essa diversidade é influenciada por questões econômicas, legais, tecnológicas, recurso e espaciais. Os grupos sociais apresentam formas diversificadas de produção, estas não são estanques e podem permanecer, alternarem ou coexistirem entre si. Há pescadores e caiçaras especializados na explotação desse ambiente, como também há aqueles que explotam vários ecossistemas diferentes, inclusive o manguezal (MOREIRA JUNIOR, 2008).

A explotação nos manguezais na região sofreu mudanças no decorrer do tempo, motivado por questões econômicas locais, ocupação do espaço, poluição, legislação ambiental e modificações nas técnicas de pesca. Os recursos explotados dos manguezais identificados são de origem animal e vegetal (MOREIRA JUNIOR, 2008).

No passado todas as comunidades estudadas viviam da explotação dos 
manguezais, porém com a ocupação, poluição e degradação desse ambiente em áreas próximas, alguns pescadores tiveram que diversificar mais suas atividades e outros até mudaram de ramo (MOREIRA JUNIOR, 2008).

Os recursos de origem animal são: aves, répteis e mamíferos como caça e o pescado, que consiste de peixes, moluscos e crustáceos que são capturados diretamente no manguezal ou em suas margens e gamboas.

Os depoimentos indicam que a caça era no passado uma importante fonte de recurso alimentar, um dos locais onde era praticada era no manguezal, ela podia ser de forma direta ou indireta. Direta era quando o caçador ia à busca de animais, como mamíferos, répteis e aves com a finalidade de capturá-los, basicamente para consumo familiar, sendo raros os casos de venda da carne. Utilizava-se de instrumentos adequados para tal, como espingardas e armadinhas. A maneira indireta era quando os pescadores ao visitarem seus apetrechos de pesca passivos que deixavam armados costumavam encontrar esses tipos de animais, muitos aproveitavam e os consumiam. A carne de animais selvagens se mostrou bastante apreciada em algumas entrevistas. Com a escassez da caça e as restrições legais essa atividade diminuiu consideravelmente, pois atualmente é considerado crime ambiental e pode acarretar a prisão do caçador. Porém o aprisionamento de aves com fins ornamentais é uma atividade que continua sendo realizada, seja para uso próprio, quanto para comércio.

Nos manguezais a pesca é a atividade mais praticada pelas comunidades estudadas, ela é realizada diretamente neles ou em suas margens e gamboas. Os peixes são capturados com estaqueada, cerco-fixo e tarrafa, e no passado, além dessas, com tribombó; os moluscos são catados manualmente; e crustáceos são capturados nestes ambientes com diversas técnicas de captura de camarão, caranguejo e siri (MOREIRA JUNIOR, 2008).

Cada comunidade estudada tem uma forma própria de lidar com este ecossistema, isto se dá devido à situação no qual se encontram os manguezais que ficam mais próximo delas e as estratégias que elas desenvolveram.

Os pescadores do Sítio Conceçãozinha, exploravam os recursos do manguezal de 
entorno, porém com a ocupação por indústrias, porto, marinas e favelas ficou inviável a pesca comercial neste ambiente, assim alguns pescadores deixaram de explotá-lo e outros buscaram manguezais mais distantes, isso fez com que a atividade pesqueira nestes locais ficasse menos atrativa. A ostra e o marisco, que no passado foram um importante recurso, atualmente não é mais pega na região. Fato similar ocorreu com o caranguejo, que devido a degradação ambiental e o número ecessivo de pescadores já não é mais uma atividade que compense economicamente. Aqueles que ainda pescam caranguejo tem que se dirijir para manguezais mais distantes.

$\mathrm{Na}$ Vila dos Pescadores a pesca do bivalve em manguezais também foi extinta devido a um conjunto de fatores, são estes a degradação ambiental, como a poluição, ocupação dos manguezais e a pesca excessiva desses moluscos, mas perciste a pesca do caranguejo e do siri de forma relevante. Nas comunidades da llha Diana e do Sítio Cachoeira os manguezais ainda são uma importante fonte de pescado, pois ainda há, no entorno dessas comunidades, grandes extensões de manguezais em boas ou rasoáveis condições, que ainda suportam a pesca comercial, porém com a degradação de extensas áreas de manguezal em outras localidades do estuário começou haver uma concentração de pescadores de outras comunidades, nas proximidades dessas comunidades, o que faz os estoques diminuirem, devido a pesca intensiva.

Os recursos vegetais do manguezal eram mais importamte para a econômia local no passado, com o tempo perderam importância. Os principais eram: as folhas, cascas e troncos para diversas finalidades, como: uso industrial, adubo, fabricação de caixotes e artefatos de madeira, extração de tanino para os curtumes, lenha e tratamento das redes de pesca.

Outro uso do mangue que merece destaque é o medicinal, Luederwaldt (1919) cita o uso do mangue com fins medicinais, como: o estrato da Rhizophora mangle empregado no tratamento de lepra; e o uso das folhas de Avecennia, que eram cozidas e utilizadas em bochecho quando se tinham dentes cariados e que causavam dor, também era usado como um enérgico adstringente. Porém em nenhum dos depoimentos foi citado tal uso, ou 
outro qualquer fim medicinal, provavelmente é uma prática que esteja em processo de extinção ou extinta.

As grandes áreas de manguezais na Baixada Santista possibilitaram a explotação de madeira para a extração de tanino desde o século $\mathrm{XVI}$, quando foram instalados os primeiros curtumes pelos colonizadores portugueses (SANTOS, 1952). Existiram vários curtumes na região, muitos deles eram pequenas instalações, com poucos empregados, muitos não tinham nem registros em órgãos oficiais do estado, isso dificulta saber ao certo o número de curtumes que havia, o número de trabalhadores que empregavam e qual a finalidade de sua produção.

Os trabalhadores que faziam a coleta de mangue eram conhecidos como "mangueiros" era um trabalho autônomo, muito árduo, realizado majoritariamente por portugueses que ganhavam por quilo de folha recolhido. Essa atividade empregava tanto a população local, quanto migrantes europeus e de outras regiões do país, que ao chegarem à região tinham essa atividade e o trabalho nos bananais como maneiras de se empregar facilmente. Assim os caiçaras locais conviviam com pessoas de diferentes regiões do Brasil e da Europa, isso propiciava intenso intercâmbio cultural. Tanto os caiçaras aprendiam coisas novas com os migrantes, quanto esses aprendiam com a população local.

Aqueles que eram de fora ao trabalharem como mangueiros, ou nos bananais, adquiriram conhecimento com a população tradicional, os trabalhadores mais antigos e pela lida diária. Assim aprendiam sobre a região, as atividades de explotação, a geografia, a dinâmica ecológica, os recursos e com esse conhecimento tinham condições de explorar outros recursos naturais, e assim, saberiam pescar e caçar, poderiam instalar um sítio para viverem e terem roça ou ainda fazerem extrativismo vegetal.

Esse conhecimento adquirido serviria mais tarde quando a atividade de fornecer recurso de mangue para os curtumes findam. Uma parte dos mangueiros e lenhadores se encerem em outras atividades, como a agricultura e a explotação, em especial a pesca.

Além das folhas e casca de mangues os curtumes utilizavam a lenha para suas caldeiras, essa era fornecida pelos "mangueiros" ou lenhadores que as retiravam dos 
manguezais, matas de restinga e Mata Atlântica. Os lenhadores constituíam-se principalmente por caiçaras e portugueses que se especializaram na extração e comércio desse recurso.

Carvalho (1944) identificou na primeira metade do século XX que, na Baixada Santista, sítios isolados exploravam a pesca e as matas para a obtenção de madeira, esta utilizada para construções, como lenha, para confeccionar canoas e artesanato. Alguns parentes e conhecidos de entrevistados trabalharam como lenhadores. Segundo os depoimentos o mercado para lenha e carvão era grande no final do século XIX e nas primeiras décadas do século XX. Diferentes segmentos necessitavam desse recurso, tais como: a industrialização incipiente; o porto de Santos; as locomotivas; padarias, hotéis e restaurantes; e as residências, pois neste período a lenha e o carvão eram o principal combustível na região. Luederwaldt (1919) cita que a lenha na época alcançava preços exorbitantes nas cidades de Santos e São Paulo.

A exploração intensiva dos mangues, matas de restinga e Mata Atlântica acarreto fortes impactos reduzido-os consideravelmente (LUEDERWALDT, 1919; CARVALHO, 1944; ANDRADE e LAMBERTI, 1965), o que fez com que houvesse a diminuição da produção dos curtumes e que ocasionou, conseqüentemente, um processo de fechamento desses estabelecimentos (GOLDEINSTEIN, 1965; GOLDEISTEIN, 1972; COUTO, 2003) até sua extinção.

Com a adoção de novas fontes de energia como a elétrica e o petróleo a lenha deixou de ter importância como fonte energética na região, assim diminuiu sua extração. A redução e posterior extinção dos curtumes e a substituição das matrizes energéticas possibilitaram a vegetação florestal uma certa recuperação, que é perdida com a posterior expansão urbana, portuária e industrial, somada a altos índices de poluição.

O ambiente natural, em especial os mangues, tratados neste texto, foram capazes de se recuperarem, pelo menos em boa parte de suas áreas. Isso devido a mudanças na economia regional, que mudou sua matriz energética e algumas de suas atividades industriais, no caso os curtumes que deixaram de existir. Boa parte daqueles antigos mangueiros e lenhadores se inserem na pesca, porém nesta mesma época, meados do 
século $X X$, a região sofre um intenso processo de urbanização, industrialização e expansão portuária, que ocupam extensas áreas, inclusive de manguezais. Soma-se a isso a instalação de várias marinas na região a partir da década de 1970.

Essa expansão se deu sobre os territórios de moradia, perambulação, agricultura e explotação dos caiçaras e pescadores artesanais. Dessa forma esses grupos sociais perderam parte de seus territórios, além dessa expansão também ter degradado grandes áreas, que continuaram a ser explotada pelas comunidades locais. Isso acarretou considerável perda dos recursos, levando às comunidades a pobreza, pois tiveram que encontrar outros pesqueiros e recursos de pesca.

Com o desenvolvimento industrial, portuário e urbano aumentou-se consideravelmente a poluição no estuário, o que gerou forte degradação ambiental, suas conseqüências foram à escassez do pescado e suas desvalorização frente aos consumidores, além disso, houve uma resistência da população em geral de consumi-los. As comunidades de pescadores assumiam o risco de se contaminar ao consumi-lo, houve considerável perda de recursos, esses fatos contribuíram para o processo de empobrecimento das comunidades.

Com a perda de grandes extensões de territórios pesqueiros e o aumento do número de pescadores devido ao crescimento do desemprego na região (MOREIRA JUNIOR, 2008), as áreas onde ainda continuou a haver pesca concentraram um número maior de pescadores, isso provocou uma sobrexplotação nestes locais, com maior disputa pelo recurso e por sua comercialização, também houve um comprometimento do estoque, o que causou sua depleção. Isso fez que muitos pescadores tivessem que arrumar formas de complementar a renda, e houve até aqueles que mudaram de profissão, pois com a pesca não conseguiam mais sustentar a família.

A legislação ambiental a fim de gerir o uso do ambiente natural, mas sem considerar as culturas e modos de vida de comunidades pesqueiras e tradicionais, restringiu o uso dos recursos naturais, como o extrativismo vegetal, isso fez com que a explotação dos recursos naturais, como caça e extração vegetal não pudessem mais ser praticados, o que também se deu como um duro golpe ao modo de vida e de produção 
tradicional. Houve aqueles que infringiam a lei a fim de assegurar seu sustento, outros aceitaram as novas normas e mudaram seu modo de produção, duas das perdas mais significativas para a pesca foram a proibição de extração de madeira para as canoas e para o cerco-fixo, a confecção da canoa esta extinta na região e a do cerco em vias de extinção. A extração de orquídeas e bromélias apesar de incipiente é uma atividade citada pela comunidade da Ilha Diana. Apesar de ninguém tê-la como meio de vida, às vezes ocorre como complementação a renda. Essa é uma atividade, que muitas vezes serve para complementar os parcos ganhos com a pesca. Mesmo sabendo do risco de sofrerem problemas com as autoridades devido as restrições da legislação ambiental os pescadores alegam que com a atual escassez do pescado é necessário buscar alternativas de renda.

As ações de degradação ambiental em conjunto causaram fortes danos ao ambiente e ao modo de vida das comunidades pesqueiras, o que acarretou sua desestruturação e grande perda cultural e conseqüentemente um acentuado empobrecimento, a tabela 1 mostra de forma sistematizada os tipos de impactos ambientais, o que o provocou, suas conseqüências e as respostas adaptativas dadas pelas comunidades, segundo seus depoimentos.

Tabela 1 - Impactos ambientais negativos de origem antrópica nos manguezais da Baixada Santista, suas causas, conseqüências e respostas adaptativas das comunidades estudadas.

\begin{tabular}{|c|c|c|c|c|}
\hline & $\begin{array}{l}\text { Tipo de impacto } \\
\text { ambiental }\end{array}$ & Fator casual & Conseqüência & Resposta \\
\hline \multirow[t]{2}{*}{ Manguezal } & Restrições legais & Legislação ambiental & $\begin{array}{c}\text { Proibição de explotar } \\
\text { madeira }\end{array}$ & $\begin{array}{l}\text { Infringir ou aceitar a } \\
\text { legislação; parar de } \\
\text { construrir cerco-fixo; } \\
\text { mudar de arte de } \\
\text { pesca; } \\
\text { empobrecimento }\end{array}$ \\
\hline & Ocupação & $\begin{array}{c}\text { Expansão urbana, } \\
\text { portuária, industrial e } \\
\text { turística }\end{array}$ & $\begin{array}{l}\text { Perda de território } \\
\text { explotação, de } \\
\text { recurso; degradação } \\
\text { ambiental }\end{array}$ & $\begin{array}{l}\text { mudar de área de } \\
\text { pesca; mudar de } \\
\text { recurso alvo; } \\
\text { empobrecimento }\end{array}$ \\
\hline
\end{tabular}




\begin{tabular}{|c|c|c|c|c|}
\hline Poluição & $\begin{array}{c}\text { Industrial, portuária, } \\
\text { urbana e turística }\end{array}$ & $\begin{array}{c}\text { Degradação } \\
\text { ambiental; } \\
\text { contaminação; } \\
\text { desvalorização do } \\
\text { pescado; deficuldade } \\
\text { de vendê-lo }\end{array}$ & $\begin{array}{c}\text { Risco de } \\
\text { contaminação; perda } \\
\text { de recurso; } \\
\text { empobrecimento }\end{array}$ \\
\cline { 2 - 5 } & $\begin{array}{c}\text { Derrubada de } \\
\text { mangue }\end{array}$ & $\begin{array}{c}\text { Embarcações de } \\
\text { recreio, apoio } \\
\text { portuário, outras }\end{array}$ & $\begin{array}{c}\text { Degradação } \\
\text { ambiental ; perda de } \\
\text { recurso }\end{array}$ & $\begin{array}{c}\text { Arrumar outra área } \\
\text { de pesca }\end{array}$ \\
\cline { 2 - 5 } & $\begin{array}{c}\text { Grande quantidade } \\
\text { de pescadores }\end{array}$ & $\begin{array}{c}\text { Grande competição } \\
\text { pela captura e } \\
\text { venda; degradação } \\
\text { ambiental; perda de } \\
\text { recurso }\end{array}$ & $\begin{array}{c}\text { Pescar mais, } \\
\text { capturar menos, } \\
\text { arrumar outra } \\
\text { atividade além da } \\
\text { pesca; mudar de } \\
\text { profissão; } \\
\text { empobrecimento }\end{array}$ \\
\hline
\end{tabular}

\section{CONCLUSÕES}

Através de depoimentos orais foi possível constatar diferentes adaptações desenvolvidas por comunidades de pescadores artesanais nos seus modos de produção a fim de superar as perdas de recursos naturais ocorridas pela degradação ambiental de origem antrópica no manguezal da Baixada Santista. As respostas dadas pelas comunidades originam-se da necessidade de sobrevivência e da percepção que elas têm dos impactos e suas possibilidades de executarem novas atividades para compensarem as perdas.

As comunidades de pescadores artesanais e caiçaras mantêm diferentes estratégias de produção do pescado a fim de superar as perdas dos recursos conseqüentes da degradação ambiental. O pescador pode apresentar uma ou diferentes maneiras de adaptar-se e de responder a degradação ambiental e a depleção dos recursos. Porém, mesmo com as tentativas de superar as perdas, os depoimentos indicam que as comunidades passam por um processo de empobrecimento e desestruturação devido a crise que a exploração dos recursos naturais, em especial a pesca se encontra a pelo menos há três décadas. 


\section{REFERÊNCIAS}

COMPANHIA ESTADUAL DE SANEAMENTO AMBIENTAL - CETESB. Avaliação do estado de degradação dos ecossistemas da Baixada Santista - SP. São Paulo:CETESB, 1991.:32 p

DIEGUES, A. C. S. Diversidade biológica e culturas tradicionais litorâneas: o caso das comunidades caiçaras. In: CONFERENNCIA DA UNIÃO INTERNACIONAL PARA A CONSERVAÇÃO DA NATUREZA E DOS RECURSOS NATURAIS, 4,1988, São José, Costa Rica. Anais...São José, Costa Rica:1988.40 p

DIEGUES, A. C. S. Povos e água: inventário das áreas úmidas brasileiras. 2 ed, São Paulo, Brasil: NUPAUB-USP,2002. $597 \mathrm{p}$

FERRI, M. G. Vegetação brasileira. Belo Horizonte, Brasil: EDUSP/Itatiaia,1980. 160 p

FREITAS, S. M. de. História oral: possibilidades e procedimentos. São Paulo, Brasil: Humanitas/FFLCH/USP: Imprensa Oficial do Estado, 2002. 95 p

GRASSO, M.; TOGNELLA, M. M. P. Utilização econômica. In: SCHAEFFER-NOVELLI, Y. (Coord.). Manguezal: ecossistemas entre a terra e o mar. São Paulo, Brasil: Caribbean Ecological Research,1995.43-47

GUIMARÃES NETO, R. B. Artes da Memória, fontes orais e relatos históricos. Revista História e Perspectiva, v.23,p.99-114, 2000.

LACERDA, L.D. de. Manguezais florestas de beira-mar. Revista Ciência Hoje, v.3, n.13,p. 62-70,1984.

LAMPARELLI, C.C. (Coord.). 1999. Mapeamento dos ecossistemas costeiros do Estado de São Paulo. São Paulo, Brasil: Secretaria do Meio Ambiente ,CETESB,1999.106 p 
LICHTI, F. M. Poliantéia de Bertioga, 1531 - 2002, da colonização ao século XXI. São Vicente, Brasil: Gráfica e Editora Vice-Rei, 2002. 602 p

LUEDERWALDT, H. Os manguesaes de Santos. Revista do Museu Paulista, Tomo 11,p. 309-409,1919.

MEIHY, J. S. B. Manual de história oral. 5 ed, São Paulo, Brasil: Edições Loyola,2005. 291 p.

MOREIRA JUNIOR, W. A pesca artesanal no complexo estuarino da Baixada Santista $(S P)$ e sua relação com os impactos ambientais na perspectiva das comunidades locais. Dissertação, Instituto de Pesca, Santos. 2008. 345 p.

PASSARINI, L. Mitografia em história oral. Revista Projeto Historia, v.10, p. 29-40,1993.

PETRONE, P. O povoamento antigo e a circulação. In: A Baixada Santista; aspectos geográficos. São Paulo, Brasil: Editora da Universidade de São Paulo ,1965.p.11-138

RIBEIRO NETO, F. B.; OLIVEIRA, M. F. Estratégias de sobrevivência de comunidades litorâneas em regiões ecologicamente degradadas: o caso da Baixada Santista. São Paulo, Brasil: F. Ford/IUCM/IOUSP,1989. $189 \mathrm{p}$

SILVA SOBRINHO, C. Romagem pela terra dos Andradas. Rio de Janeiro, Brasil: Edição do autor ,1957.242 $\mathrm{p}$

VIERTLER, R. B. Métodos antropológicos como ferramenta para estudo em etnobiologia e etnoecologia. In: AMOROSO, M. C. de M.; MING, L. C. PEREIRA DA SILVA, S. M. Métodos de coleta e análise de dados em etnobiologia, etnoecologia e disciplinas correlatas. Rio Claro: Sociedade Brasileira de Etnobiologia e Etnoecologia/ UNESP,2002. 205 p. 